\title{
USE OF CUMULATIVE DISTRIBUTION FUNCTIONS IN ORDER TO ESTIMATE DAMAGE PROBABILITY
}

\author{
Ali GÜRBÜZ1 ${ }^{1}$, AND MUHAMMED TEKIN ${ }^{2}$ \\ ${ }^{1}$ University of Recep Tayyip Erdogan, Department of Civil Engineering, \\ ali.gurbuz@erdogan.edu.tr \\ ${ }^{2}$ Gelisim University, Department of Civil Engineering, \\ mtekin@gelisim.edu.tr
}

\begin{abstract}
In this study, the cumulative distribution function was formed to estimate the probability of earthquake damage risk of the residential buildings. Nonlinear Pushover analysis was performed to 25 reinforced concrete residential buildings. The information regarding the buildings was taken from their projects. A $3 D$ computer model was drawn for each building and analysis was applied to these models. 4 damage limits (slight, moderate, extensive and complete) and 5 damage zones (undamaged, slight, medium, extensive and collapse) were determined on the modal capacity curves of the buildings. Probability density functions were calculated with the help of lognormal mean and lognormal standard deviation values of limit states. The cumulative distribution functions were generalized and the probability of the damage was shown. With the results of this work; damage possibility can be estimated for any reinforced concrete residential building which has same features such as soil type, story height, irregularities, soft story etc.
\end{abstract}

Keywords: Cumulative distribution function, fragility curves, damage estimation

1. Introduction. In probability theory and statistics, the cumulative distribution function (CDF), describes the probability that a real-valued random variable " $\mathrm{X}$ " with a given probability distribution will be found to have a value less than or equal to $\mathrm{x}$ (Zwillinger and Kokoska 2010). In the case of a continuous distribution, it gives the area under the probability density function from minus infinity to " $x$ ". Cumulative distribution functions are also used to specify the distribution of multivariate random variables (Gentle 2009). As for, the loss estimation methods; earthquake loss estimation method is based on the damage states of the structures and there are several models which can be used to quantify the damages, characterization of damage state and estimation of losses after the earthquakes (FEMA 1997, Hamid and Mohamad 2013). Fragility analysis is one of the key components in seismic risk assessment and more specifically in regional seismic risk assessment.

As part of these procedures, fragility curves are employed in order to estimate the damage of a building after various intensities of ground motion shaking (Porter, Kiremidjian et al. 2001, Lignos and Karamanci 2013). Fragility curves express the probability of the structure reaching or exceeding various damage states as a function of a specific earthquake intensity measure. The function of fragility curves can be assumed as a cumulative distribution function, such as a normal distribution, lognormal distribution or beta distribution (Rota, Penna et al. 2008, Park, Towashiraporn et al. 2009, Rota, Penna et al. 2010, Bessason, Bjarnason et al. 2012, Hsieh, Lee et al. 2013).

In this study; CDF was used as a loss estimation method. There are many other loss estimation methods but fragility curve are useful tool for earthquake damage estimation studies in recent years (Serdar Kircil and Polat 2006; Gentle 2009; Su and Lee 2013.

\section{Eartquake hazard for turkey}

Turkey has a population of more than seventy five million. A large part of our country located in "earthquake 
zone" according to "Earthquake Zoning Map for Turkey (ÖZMEN, NURLU et al. 1997). Thousands of earthquakes have been recording every year in Turkey according to Republic of Turkey, Disaster and Emergency Management Presidency (DEMP). Turkey is constantly threatened by earthquakes and more than 100,000 people have died because of earthquakes in Turkey in the last hundred years(TUDAP 2005). Many of existing buildings have either collapsed or sustained extensive damage during the past earthquakes because of low quality concrete, poor confinement of the end regions of columns and beams or similar reasons (ÇÖĞÜRCÜ, DÖNDÜREN ET AL, 2006, HAKTANIR, T. ARI, K., 2007).

Thus, there has been an increasing importance on the danger of earthquake disasters and seismic risk assessments have become one of the necessary issue for earthquake loss estimates (Shibata 2006, Hsieh, Lee et al. 2013).

The loss estimation is based on the damage states of the structures and there are several models which can be used to quantify the damages, characterization of damage state and estimation of losses after the earthquakes (FEMA 1997, Hamid and Mohamad 2013). Fragility analysis is one of the key component in seismic risk assessment and more specifically in regional seismic risk assessment(Abo-El-Ezz, Nollet et al. 2013).

3. Description of the proposed methodology. It is possible to use linear or nonlinear methods in seismic analyses of structures. Linear analysis uses the methods of the elastic solution. Inelastic behavior includes to solution by specific coefficients. Results obtained from elastic analyses are lower realistic than inelastic analyses(Tekin, Gürbüz et al. 2013). It is need to include inelastic behavior of structural elements for more realistic results. Nonlinear time history $(\mathrm{TH})$ analysis is the represents the most actual behavior of the structure. However, developing computer technologies provide easy to carry out it. TH analyses need to long time period bacause of multi-parameter solution way. Seismic loads are applied to the building directly in TH method. Earthquake data should be selected carefully. Past studies shows that nonlinear pushover (NSP) analysis is suitable alternative to TH by correct selection of parameters and assumptions (Saidi and Sozen 1981).

In this study; cumulative distribution function (cbf) was preferred to analyze the probability of earthquake damages. CBF was preferred as a earthquake damage probability analyze in recent researches. The results of $\mathrm{CBF}$ are called as fragility curves at these researches. Fragility curve is a useful tool for predicting earthquake risk of buildings with similar characteristics such as material, height and design code level(Abo-El-Ezz, Nollet et al. 2013). The curves can be formed empirical, heuristic or analytical based methods(Singhal and Kiremidjian 1996, Porter, Kiremidjian et al. 2001, Rossetto and Elnashai 2003, Wu, Tesfamariam et al. 2012, Zhang and $\mathrm{Hu} 2005$ ). The principle of the analytical method which is preferred in this study is to analyze the damage state of structures (Hsieh, Lee et al. 2013). Nonlinear static pushover analyze was performed on 3D computer models of the buildings. The reference design spectrum which has $10 \%$ probability of exceeding in 50 years was used according to TEC 2007.

In addition, fragility curves are cumulative distribution functions that probability of reaching or exceeding a damage state as demand parameters such as story drift ratio(SDR), peak ground acceleration (PGA), spectral acceleration (Sa) or spectral displacement (Sd) (Serdar Kirçil and Polat 2006, Lignos and Karamanci 2013, Su and Lee 2013), (Hsieh, Lee et al. 2013, Suppasri, Charvet et al. 2013). It has been widely accepted that spectral displacement can be closely correlated with seismic damage of structures(Serdar Kirçil and Polat 2006) (Su and Lee 2013).

Probability density function of a random variable with lognormal distribution is as follows equation-1:

$$
f(x)=\frac{1}{x \sigma_{Y} \sqrt{2 \pi}} \exp -\left[-\frac{\left(\ln x-\mu_{Y}\right)^{2}}{2 \sigma_{Y}{ }^{2}}\right],(0<x<+\infty)
$$

In this distribution; $\mu_{Y}$ is lognormal mean of variable $\mathrm{Y}$ and $\sigma_{Y}$ is lognormal standard deviation of variable Y. $\mu_{X}$ ve $\sigma_{X}$ are associated with $\mu_{Y}$ ve $\sigma_{Y}$ by equation-2 and equation-3.

$$
\begin{gathered}
\mu_{Y}=\ln \left[\mu_{X} / \sqrt{\left(\frac{\sigma_{X}{ }^{2}}{\mu_{X}{ }^{2}}+1\right)}\right] \text { (Eq.2) } \\
\sigma_{Y}=\sqrt{\ln \left(\frac{\sigma_{X}^{2}}{\mu_{X}^{2}}+1\right)} \text { (Eq.3) }
\end{gathered}
$$


Probability of having a specific range of a continuous random variable can be written as equation-4:

$$
P(a<X \leq b)=\frac{1}{\sqrt{2 \pi}} \int_{\mathrm{x}=\mathrm{a}}^{\mathrm{x}=\mathrm{b}} \mathrm{f}(\mathrm{x}) \mathrm{dx}=\int_{\mathrm{x}=\mathrm{a}}^{\mathrm{x}=\mathrm{b}} \frac{1}{x \sigma_{Y} \sqrt{2 \pi}} \exp -\left[-\frac{\left(\ln x-\mu_{Y}\right)^{2}}{2 \sigma_{Y}{ }^{2}}\right] d x(\text { Eq.4) }
$$

Probability distribution of earthquake damage is assumed to be lognormal distribution. Thus, the analytical expression of fragility curve for a damage level is written as the follows equation-5

$$
P d \geq\left(d_{S_{i}} \mid S_{d}\right)=\varphi\left(\frac{\ln \left(S_{d}\right)-\overline{S_{d_{s_{i}}}}}{\beta_{d_{s_{i}}}}\right)(\text { Eq.5) }
$$

Pd is probability of damage. Sd is modal displacement. $d_{S_{i}}$ is modal displacement for damage level "i". $\overline{S_{d_{s_{i}}}}$ is mean modal displacement for damage level "i". $\beta_{d_{s_{i}}}$ is lognormal standard deviation of modal displacement values for damage level "i". $\varphi$ is cumulative distribution function. Fragility curves can be formed empirical, analytical or heuristic based methods (Singhal and Kiremidjian 1996, Porter, Kiremidjian et al. 2001, Rossetto and Elnashai 2003, Wu, Tesfamariam et al. 2012, Zhang and Hu 2005 ). In this study, analytical fragility curves were obtained by nonlinear static pushover analysis. NSP analysis can be applied with two different ways. One of them is force controlled and the other one is displacement controlled analysis method. In this study, displacement controlled analysis method was applied.

In addition to this, NSP analysis is employed by CSI SAP2000 computer program to obtain the base shears against roof displacements relationship for existing buildings. Besides analytical fragility curves were obtained by spectral displacement values of modal capacity curves. End point of linear part of the curve was assumed as "slight damage limit". Intersection point of idealized line was assumed as "moderate damage limit", The Last point of modal capacity curve was assumed as "complete damage limit". Finally; midpoint of the moderate and complete damage limits was assumed as "extensive damage limit. Obtaining of damage levels as shown in Figure 3.1.

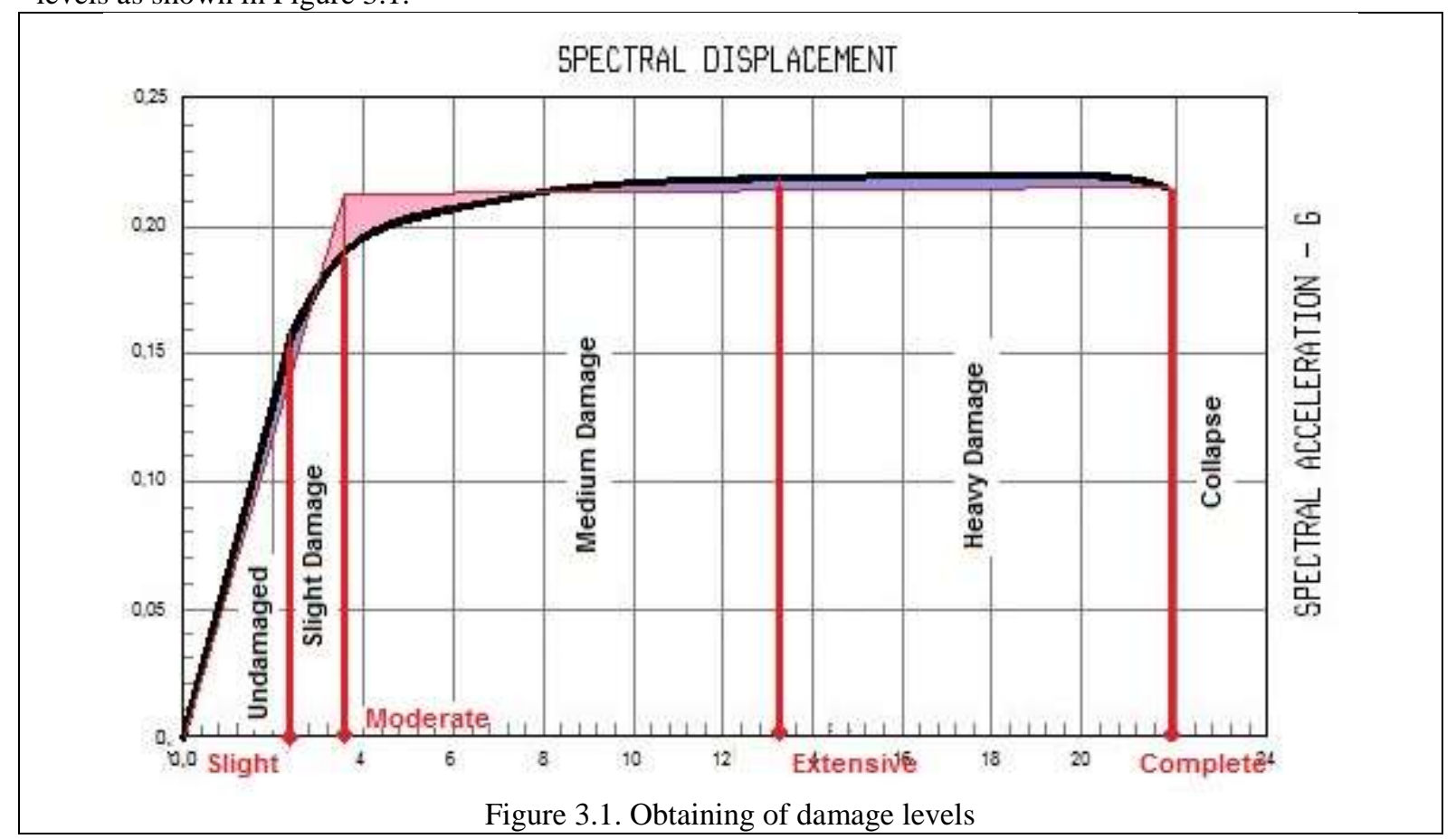

4. Building Inventory. 90\% of total building stock of Turkey are Low and midrise buildings. Thus; 3, 4 and 5 storey reinforced concrete residential buildings discussed about earthquake hazard and analytical fragility curves performed for 25 residential RC buildings with 3, 4 and 5 storey in this study. The buildings were selected by random sampling method. They were evaluated using their projects. Table 3.1 shows the information about buildings 
Table 3.1; Building inventory

\begin{tabular}{|c|c|c|c|c|}
\hline Building Code & $\begin{array}{l}\text { Number of } \\
\text { Story }\end{array}$ & Soil Type & Concrete & $\begin{array}{l}\text { Reinforcemen } \\
t\end{array}$ \\
\hline B_01 & 4 & $\mathrm{Z3}$ & C14 & S220 \\
\hline B_02 & 4 & $\mathrm{Z4}$ & C16 & S220 \\
\hline B_03 & 3 & $\mathrm{Z4}$ & C14 & S220 \\
\hline B_04 & 4 & Z3 & C14 & S220 \\
\hline B_05 & 4 & $\mathrm{Z3}$ & C14 & S220 \\
\hline B_06 & 5 & $\mathrm{Z3}$ & C14 & S220 \\
\hline B_07 & 5 & Z3 & C14 & S220 \\
\hline B_08 & 5 & $\mathrm{Z3}$ & C16 & S220 \\
\hline B_09 & 5 & $\mathrm{Z4}$ & C14 & S220 \\
\hline B_10 & 4 & $\mathrm{Z3}$ & C14 & S220 \\
\hline B_11 & 4 & $\mathrm{Z3}$ & C14 & S220 \\
\hline B_12 & 5 & $\mathrm{Z} 2$ & C14 & S220 \\
\hline B_13 & 4 & $\mathrm{Z3}$ & C16 & S220 \\
\hline B_14 & 3 & $\mathrm{Z4}$ & C14 & S220 \\
\hline B_15 & 4 & $\mathrm{Z2}$ & C14 & S220 \\
\hline B_16 & 5 & $\mathrm{Z3}$ & C14 & S220 \\
\hline B_17 & 5 & $\mathrm{Z3}$ & C16 & S220 \\
\hline B_18 & 3 & $\mathrm{Z4}$ & C16 & S220 \\
\hline B_19 & 5 & $\mathrm{Z4}$ & $\mathrm{C} 14$ & S220 \\
\hline B_20 & 4 & $\mathrm{Z3}$ & C14 & S220 \\
\hline B_21 & 4 & $\mathrm{Z3}$ & C14 & S220 \\
\hline B_22 & 5 & $\mathrm{Z3}$ & C14 & S220 \\
\hline B_23 & 5 & $\mathrm{Z} 3$ & C10 & S220 \\
\hline B_24 & 3 & $\mathrm{Z4}$ & C14 & S220 \\
\hline B_25 & 5 & $\mathrm{Z} 3$ & C14 & S220 \\
\hline
\end{tabular}

5. Analytical results. The principle of the analytical method is based on nonlinear static analyze. Thus, a 3D computer model was occurred for each building to analyze the damage state of structures. As for the modeling issues; columns defined as reinforced concrete elements which work for axial load, M2 and M3 moment. Beams also defined as reinforced concrete element which working M3 moment. The rigid diaphragm effect was modeled using "joint constrains" properties. Otherwise, "Adopted Kent Park model" was used for nonlinear behavior of concrete. Damping of the building was considered as \%5. Each procedure was applied for all buildings. Totally, 50 modal capacity curves were obtained. Figure 5.1 shows that modal capacity 
curves of buildings for weak direction as an example.

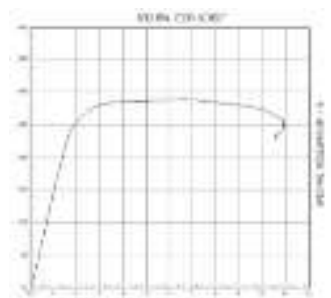

B_01

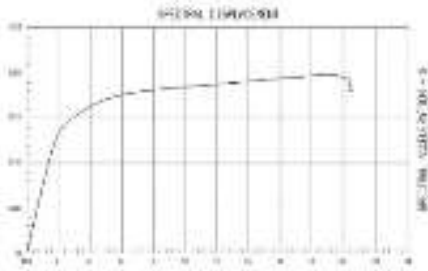

B_04

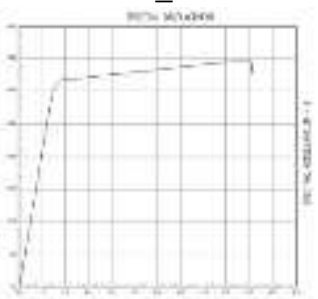

B_07

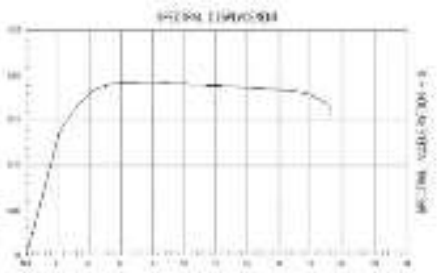

B_11

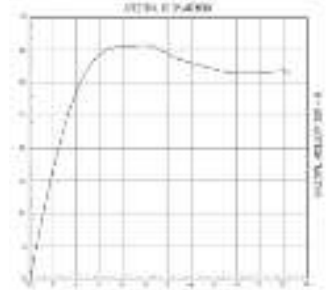

B_14

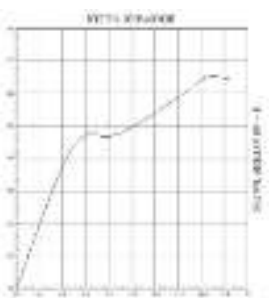

B_17

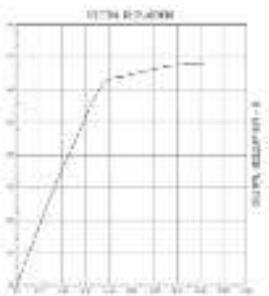

B_02

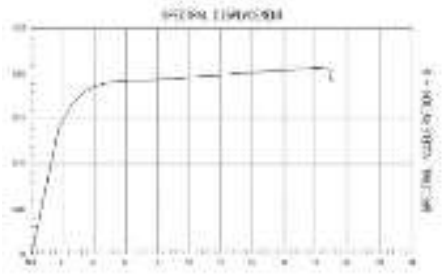

B_05

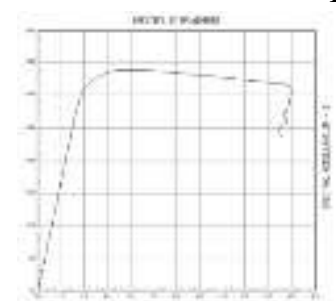

B_08

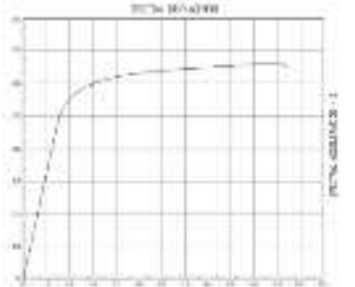

B_12

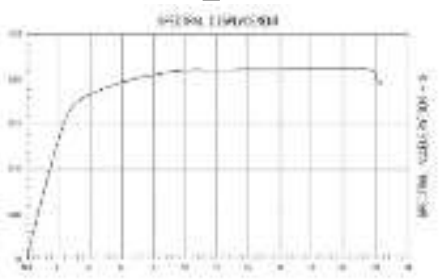

B_15

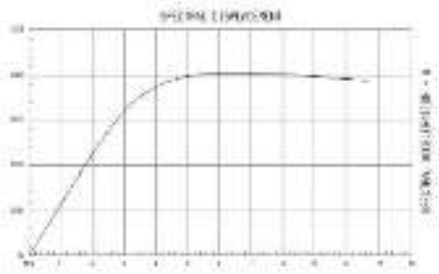

B_18

B_09

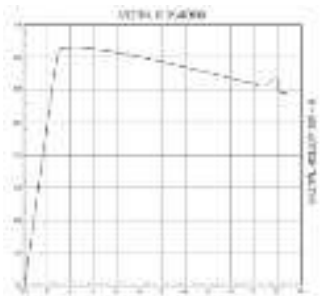

B_03

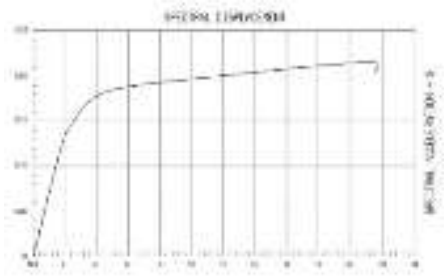

B_06

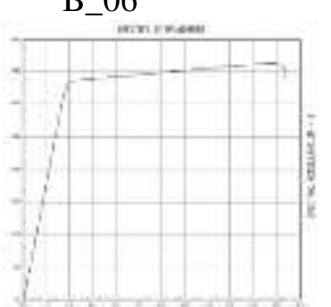

B_10

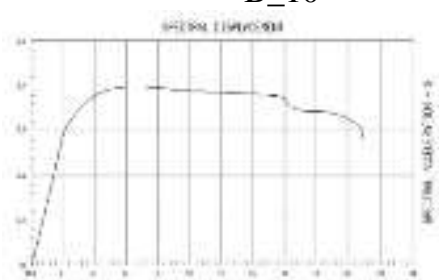

B 13

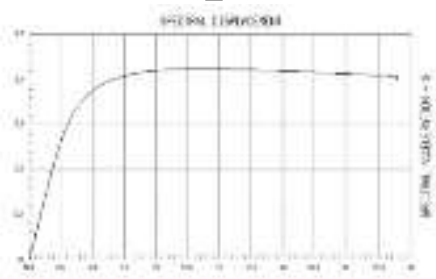

B_16

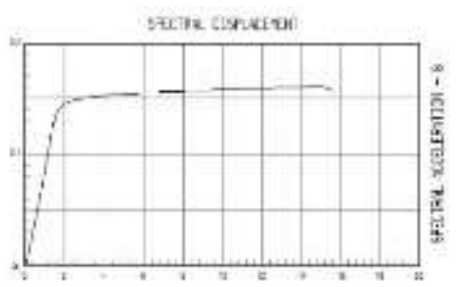

B_19 


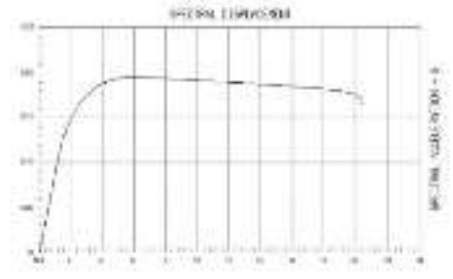

B_20

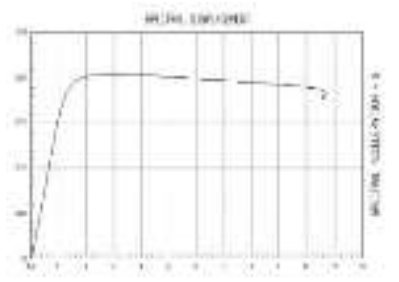

B_23

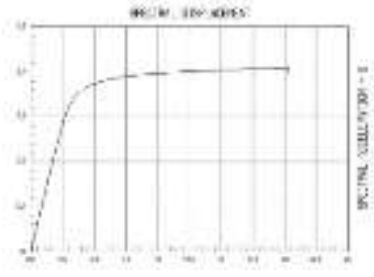

B_21

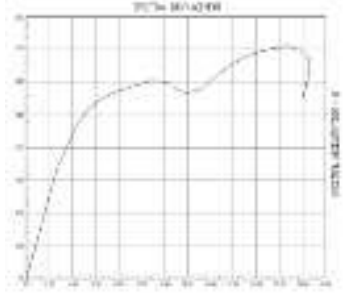

B_24

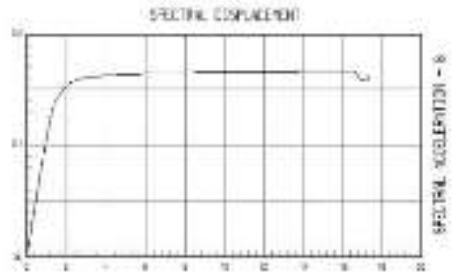

B_22

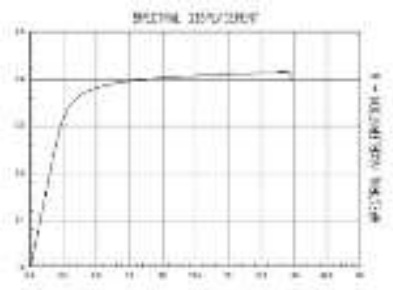

B_25

Figure 5.1; Modal capacity curves for weak direction

After the obtaining modal capacity curves; spectral demand values were calculated for related soil type according to TEC 2007. An example about obtaining of spectral demand from design earthquake demand spectrum for Z2 soil class is shown in Figure 5.2.

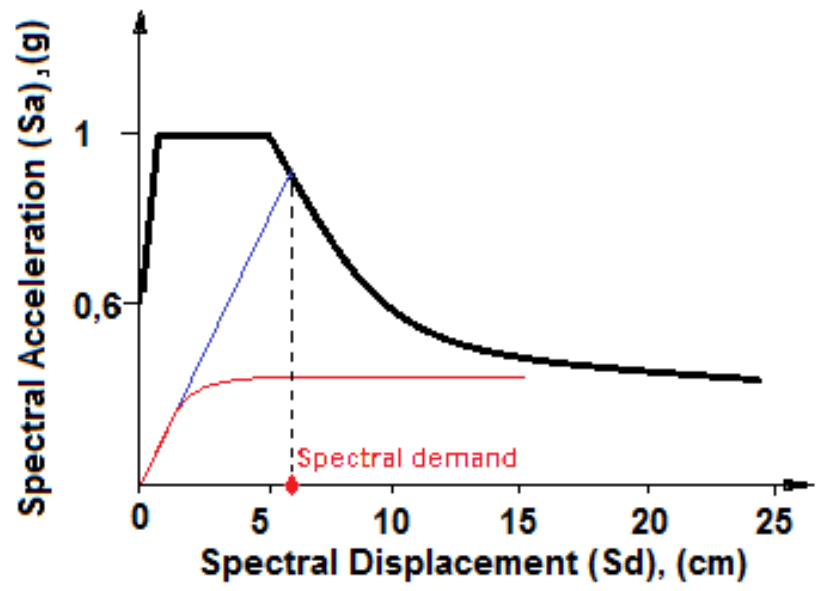

Figure 5.2. Design earthquake demand spectrum for Z2 soil class according to TEC 2007

Mean modal displacement and lognormal standard deviation of modal displacement values were utilized. Fragility curves are assumed cumulative distribution functions that probability of reaching or exceeding a damage state as demand parameters spectral displacement.

Thus, probability density functions were calculated for four damage levels. Figure 5.3 shows probability density function graphics for four damage limits. 

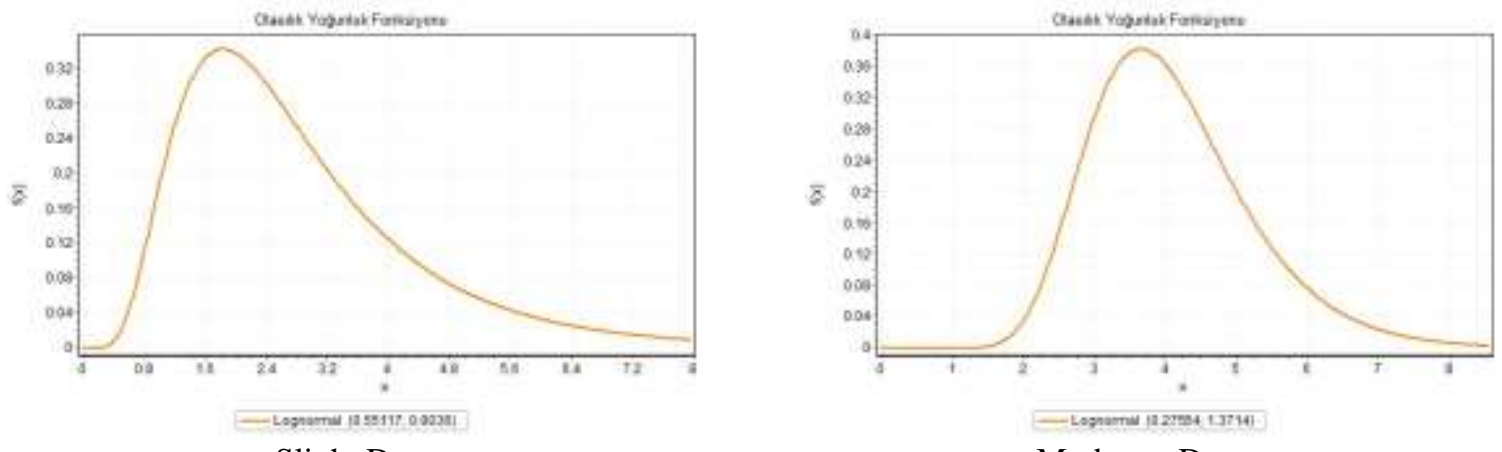

Slight Damage

Moderate Damage

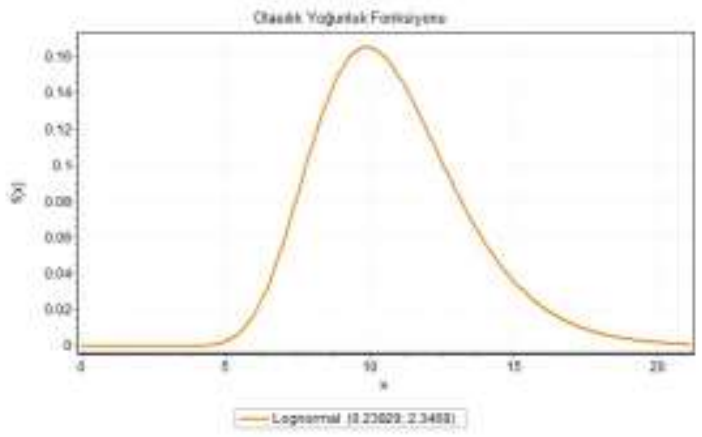

External Damage

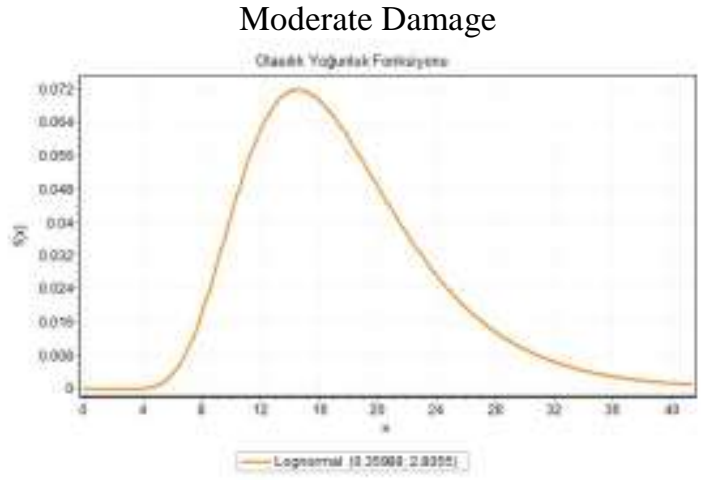

Complete Damage

Figure 5.3. Probability density function graphics

The area under the line shows that probability of damage in probability density functions. Figure 5.4 shows the transformation of probability density function to cumulative distribution function.

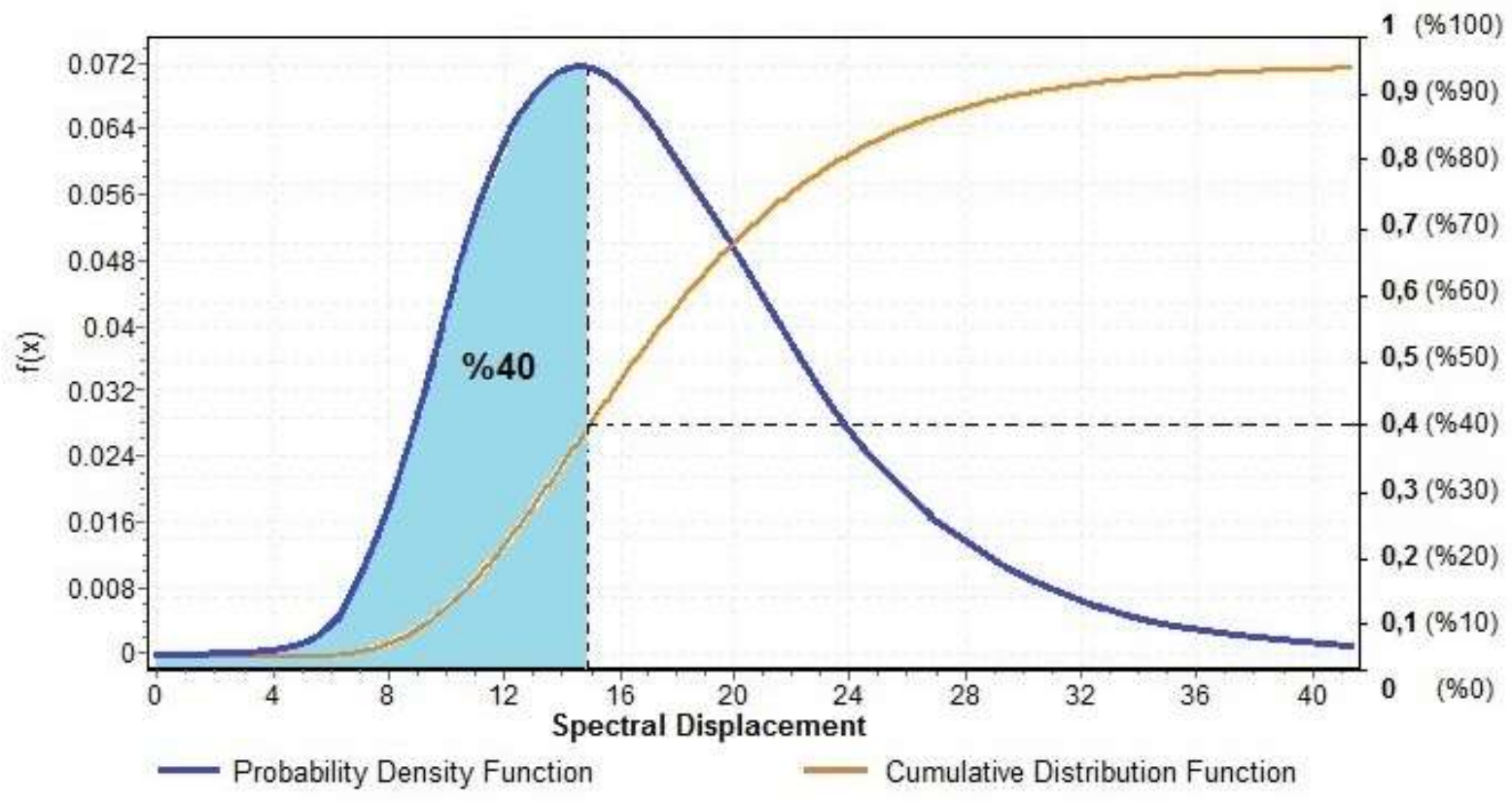

Figure 5.4; Transformation of probability density function to cumulative distribution function.

Fragility curves of slight, moderate, external and complete damage level for all buildings are shown in Figure 5.5 . 


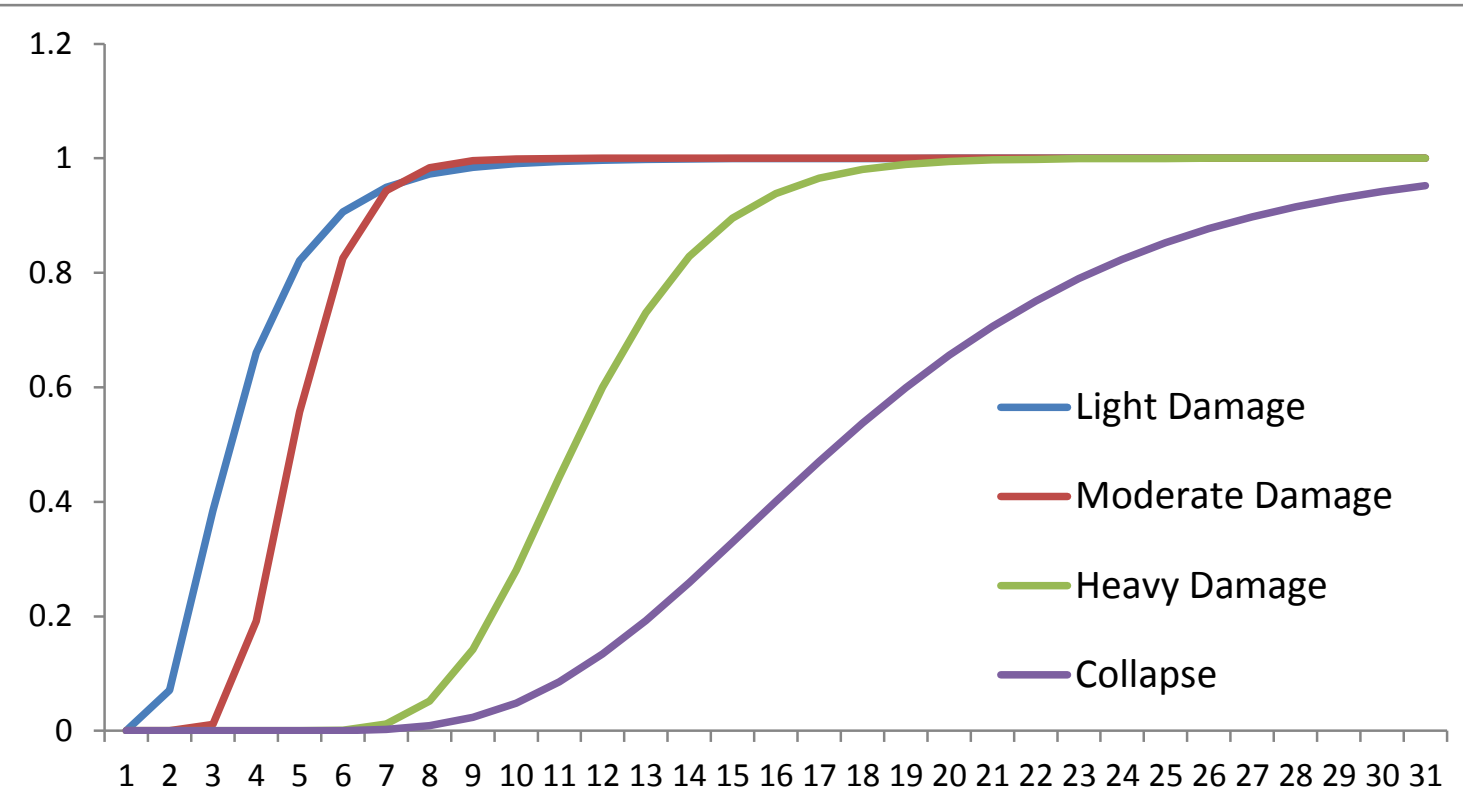

Figure 5.5. Fragility curves

6. Conclusion. In this study, cumulative distribution functions were formed to 25 reinforced concrete residential buildings with 3, 4 and 5 storey. 3D computer model was drawn for each building and analysis was applied to these models. 4 damage limits (slight, moderate, extensive and complete) and 5 damage zones (undamaged, slight, medium, heavy and collapse) were determined on the modal capacity curves of the buildings. Probability density functions were calculated with the help of lognormal mean and lognormal standard deviation values of limit states. Then, fragility curves that show probability of the damages according to design earthquake were generalized. According to pushover results; plan asymmetric buildings have lower lateral capacity compared to asymmetric buildings. However modal capacity curves give information about the current status of the buildings, there are lots of building located in seismic zones. Therefore, regional studies and rapid risk assessment methods are required. Therewith, a general assessment can be made by the results of the fragility curves.

Analyzied buildings would be situated in undamaged zone with more than $\% 50$ probabilities in the range of $0-2,50 \mathrm{~cm}$ modal displacement. There is more than $\% 50$ probabilities for the buildings to be situated in slight damage zone in the range of $2.50-3.00 \mathrm{~cm}$, moderate damage zone in the range of $3,00-6,00 \mathrm{~cm}$, extensive damage zone in the range of $6,00-9,00 \mathrm{~cm}$ and collapse zone above $9,00 \mathrm{~cm}$.

By the result of this study, cumulative distribution functions were applied as an earthquake damage estimation graphics. It is shown that; cumulative distribution functions should be use as a fragility curve for reinforced concrete buildings.

\section{REFERENCES}

[1] Zwillinger, Daniel; Kokoska, Stephen (2010). CRC Standard Probability and Statistics Tables and Formulae. CRC Press. p. 49. ISBN 978-1-58488-059-2.

[2] Gentle, J.E. (2009). Computational Statistics. Springer. ISBN 978-0-387-98145-1. Retrieved 2010-08-06.

[3] Abo-El-Ezz, A., M.-J. Nollet and M. Nastev (2013). "Seismic fragility assessment of low-rise stone masonry buildings." Earthquake Engineering and Engineering Vibration 12(1): 87-97.

[4] Hsieh, M.-H., B.-J. Lee, T.-C. Lei and J.-Y. Lin (2013). "Development of medium- and low-rise reinforced concrete building fragility curves based on Chi-Chi Earthquake data." Natural Hazards 69(1): 695-728.

[5] Lignos, D. G. and E. Karamanci (2013). "Drift-based and dual-parameter fragility curves for concentrically braced frames in seismic regions." Journal of Constructional Steel Research 90: 209-220. 
[6] Porter, K. A., A. S. Kiremidjian and J. S. LeGrue (2001). "<TR139_Porter.pdf>." Earthquake Spectra 17(2): 291-312.

[7] Rossetto, T. and A. Elnashai (2003). "Derivation of vulnerability functions for European-type RC structures based on observational data." Engineering Structures 25(10): 1241-1263.

[8] Serdar Kirçil, M. and Z. Polat (2006). "Fragility analysis of mid-rise R/C frame buildings." Engineering Structures 28(9): 1335-1345.

[9] Singhal, A. and A. S. Kiremidjian (1996). "Method for Probabilistic Evaluation of Seismic Structural Damage." Journal of Structural Engineering 122(12): 1459-1467.

[10] Su, R. K. L. and C.-L. Lee (2013). "Development of seismic fragility curves for low-rise masonry infilled reinforced concrete buildings by a coefficient-based method." Earthquake Engineering and Engineering Vibration 12(2): 319-332.

[11] Suppasri, A., I. Charvet, K. Imai and F. Imamura (2013). "Fragility curves based on data from the 2011 Great East Japan tsunami in Ishinomaki city with discussion of parameters influencing building damage." Earthquake Spectra: 131218125838008.

[12] Tekin, M., A. Gürbüz and A. Demir (2013). "COMPARISON OF NONLINEAR STATIC AND DYNAMIC ANALYSES ON A

[13] R/C BUILDING " Mathematical and Computational Applications 18 (3): 264-272.

[14] Wu, D., S. Tesfamariam, S. F. Stiemer and D. Qin (2012). "Seismic fragility assessment of RC frame structure designed according to modern Chinese code for seismic design of buildings." Earthquake Engineering and Engineering Vibration 11(3): 331-342.

[15] Zhang, J. and S. Hu ( 2005 ). "State of the Art of Bridge Vulnerability Analysis Research." Structural Engineers 21(5): 76-80.

[16] M. Saiidi and M. A. Sozen, Simple nonlinear seismic analysis of R/C structures. Journal of the Structural Division, ASCE 107, 937-51, 1981. 